\title{
A CONSTANT-CHANGE (SINGLE INJECTION) METHOD FOR THE ESTIMATION OF THE VOLUME OF DISTRIBUTION OF SUBSTANCES IN BODY FLUID COMPARTMENTS
}

\author{
By PETER P. POULOS 1 ASSISTED BY JOHN G. PULOS, MARGIE PIFER, WANDA \\ VAN WOERT, AND MARY ELLEN PARKS \\ (From the Second Surgical (Cornell) Division, Bellerue Hospital, New York, N. Y.)
}

(Submitted for publication October 4, 1954 ; accepted April 24, 1956)

There are at least two problems in estimating the volume of a body fluid compartment. First, a substance must be found which is distributed in the volume to be measured, and second, a method must be made available which will measure the distribution of the substance. In the literature, substance and method are rarely, if ever, separated. Kruhoffer (1), for example, states that an ideal indicator of the extracellular fluid space should possess the following properties: " 1 ) When sufficient time has elapsed for complete distribution the material must be found everywhere in the extracellular fluid and exclusively there and the concentrations of it must be uniform throughout the interstitial fluid and throughout plasma water, the ratio between the concentrations in the two compartments being a known fixed figure. 2) It must not be eliminable from the extracellular space. 3 ) It must not possess so high an osmotic pressure, that it causes a perceptible displacement of water from the intracellular to the extracellular space. 4) not to be toxic." When complete distribution has been attained for a non-electrolytic indicator of this kind, the extracellular fluid volume may be calculated as follows:

Extracellular Volume

$$
=\frac{\text { quantity injected }}{\text { concentration in plasma water }}
$$

Since the simple dilution method is being used, the substance must be uniformly distributed and remain in the extracellular space. Kruhoffer further states that, for substances administered in a single dose, the replacement of the quantity injected by the quantity injected minus the quantity excreted in the urine is not without error-"In such a procedure, on account of the continuous excretion, an equilibrium between the concentra-

1 Present address: Department of Surgery, Manhattan Veterans Hospital, 408 1st Avenue, New York, New York. tions of the indicator substances in plasma and interstitial fluid is never attained." To establish an equilibrium, Kruhoffer felt that two methods could be used: "1) After a large initial dose the substance might be administered by steady, continuous infusion to keep the plasma concentration constant until distribution was complete. 2) The organs of excretion (the kidneys) might be removed prior to administration." It is clear that equilibrium, as used by Kruhoffer for a non-electrolyte, means constant and equal concentrations of the indicator in both the interstitial fluid and plasma water. Whether or not such an equilibrium is obtained by either nephrectomy or a continuous infusion is difficult to prove by experimentation. It is evident that the simple dilution method has determined, to a certain extent, what the behavior of the substance should be in the body.

Guadino and Levitt (2) further defined an ideal substance for measuring extracellular fluid as one which distributed fairly rapidly and uniformly, and was eliminated slowly from the body. Furthermore, they felt that a substance such as inulin, which is rapidly excreted by glomerular filtration, is prevented from being uniformly distributed throughout the extracellular space after a single injection. These authors utilized the constant-infusion method for estimating the volume of the extracellular fluid, and again the method dictates the required behavior of the indicator. Fundamentally, the purpose of the constant infusion is to obtain uniform distribution of the substance between all compartments of the extracellular space. More exactly, since only the plasma concentration can be measured readily, the aim is to obtain the same concentration of the indicator in the interstitial and the intravascular spaces and to maintain this equal concentration over a long enough period so that it can be measured. Obviously, this cannot be done with a single injection 
because the indicator concentration is constantly changing in both compartments. However, this does not mean, as repeatedly reported (2-5), that a single injection of a substance cannot be used to measure the "extracellular volume." Most probably, a single injection cannot be used if the calculation for the volume of distribution of the indicator is made on the basis of the constant-infusion method. The method which is used to determine the distribution of the substance must necessarily take into account the behavior of the substance after it has been introduced into the body. With the constant-infusion method, equilibrium is indicated by a constancy of the plasma concentration of the indicator, and the error involved in assuming uniform distribution of the indicator may well be insignificant.

Another commonly used single injection method for estimating the volume of distribution of substances is the extrapolation method, as used, for example, by Cardozo and Edelman (6). Serum concentrations are plotted semi-logarithmically against time and the "equilibrium" concentration is obtained by extrapolation to the time of commencement of infusion (zero time). Theoretically, the method can only be used with substances which have a constant clearance from the time of the injection. Newman, Bordley, and Winternitz (7) assumed constant clearance of the substance in deriving the equation which relates the volume of distribution of a non-metabolized substance to the renal clearance and the time decrement of the natural logarithm of the plasma concentration. Again, the method severely restricts the permissible behavior of the substance.

The purpose of this communication is to introduce a single injection method, given the name of the constant-change method, for calculating the apparent distribution of substances in an intact animal. The method is independent of the amount of indicator injected, and from the theoretical point of view, does not require that the substance be uniformly distributed in the fluid compartment which is being measured and, thus treats the plasma and interstitial concentrations of the indicator as being unequal and constantly changing. The method has been compared directly with two single injection methods, the simple dilution (with excretion) and extrapolation methods, and with the constant-infusion method. Inulin was used as the indicator in man, and simultaneously injected mannitol and sucrose was used in dogs. The method has been found to be superior to the other single injection methods, and at least equal to the constant-infusion method. An attempt has been made to define steady state conditions between plasma and interstitial fluids after a single injection of an indicator.

\section{THEORETICAL CONSIDERATIONS}

The derivation of the general equation used for the estimation of one fluid compartment will be considered first. Then, similar equations for dealing with two or more compartments will be developed.

1. One compartment: If a given amount of a substance, $A$, is injected into a fluid volume, $V$, and $U$ is the loss of the substance from the volume (Figure 1a), then the amount of substance injected must be equal to the amount of substance in the volume plus that which has been lost. Thus, if no substance is created or destroyed, then

$$
\mathrm{A}=\mathrm{CV}+\mathrm{U}
$$

where $\mathrm{C}$ equals the average concentration of the substance in volume V. If now one differentiates with respect to time,

$$
0=v \frac{d C}{d t}+\frac{d U}{d t}
$$

or

$$
\mathrm{V}=-\frac{\mathrm{dU} / \mathrm{dt}}{\mathrm{dC} / \mathrm{dt}}
$$

or

$$
\text { Volume }=\frac{\text { Instantaneous rate of change of } U \text { with time }}{\text { Instantaneous rate of change of } C \text { with time }}
$$

2. Two compartments: The above volume, $\mathrm{V}$, is now divided into two compartments, $V_{1}$ and $V_{2}$, which are separated by a permeable membrane so that $V_{2}$ is about three times larger than $V_{1}$ (Figure $1 b$ ). The substance $A$ is injected into volume $V_{1}$ and distributes into volume $V_{2}$. At any time after the injection of the indicator, the continuity equation becomes

where

$$
A=C_{1} V_{1}+C_{2} V_{2}+U
$$

$A=$ amount of substance injected into compartment $V_{1}$;

$C_{1}=$ average concentration of the substance in compartment $\mathrm{V}_{\mathbf{1}}$;

$\mathrm{C}_{2}=$ average concentration of the substance in compartment $\mathrm{V}_{2}$;

$\mathrm{U}=$ amount of substance lost from the volume.

An expression must be obtained for the total volume, $\mathrm{V}_{1}+\mathrm{V}_{2}$. So to equation (4) add and subtract the quantity $\mathrm{C}_{1} \mathrm{~V}_{2}$,

$$
\mathrm{A}=\mathrm{C}_{1} \mathrm{~V}_{1}+\mathrm{C}_{2} \mathrm{~V}_{2}+\mathrm{U}+\mathrm{C}_{1} \mathrm{~V}_{2}-\mathrm{C}_{1} \mathrm{~V}_{2}
$$

and regroup the terms, so that

$$
A=C_{1}\left(V_{1}+V_{2}\right)+V_{2}\left(C_{2}-C_{1}\right)+U
$$


Now, differentiating with respect to time, one obtains,

or

$$
0=\left(V_{1}+V_{2}\right) \frac{d C_{1}}{d t}+V_{2} \frac{d}{d t}\left(C_{2}-C_{1}\right)+\frac{d U}{d t}
$$

$$
V_{1}+V_{2}=-\frac{V_{2} \frac{d}{d t}\left(C_{2}-C_{1}\right)+\frac{d U}{d t}}{d C_{1} / d t}
$$

If $\mathrm{C}_{2}, \mathrm{dU} / \mathrm{dt}$, and $\mathrm{dC}_{1} / \mathrm{dt}$ cannot be measured, certain simplifying assumptions must be made in order to obtain a useful equation. The quantity $\left(C_{2}-C_{1}\right)$ may be assumed to remain constant, then the term $V_{2} \frac{d}{d t}\left(C_{2}-C_{1}\right)$ becomes zero. In other words, if the difference in the concentrations of the substance in volumes $V_{1}$ and $V_{2}$ remains constant, the term $V_{2} \frac{d}{d t}\left(C_{2}-C_{1}\right)$ becomes zero because the derivative of a constant is zero, and the expression becomes

or

$$
V_{1}+V_{2}=-\frac{d U / d t}{d C_{1} / d t}
$$

Total Instantaneous rate of change of $U$ with time Volume $=\frac{\text { Instantaneous rate of change of } C_{1} \text { with time }}{\text { Int }}$

It should be noted that, in assuming that $C_{2}-C_{1}$ remains constant, the constant may vary from zero to infinity. If the constant is zero, then $C_{2}=C_{1}$, and this would indicate that uniform distribution of the indicator is assumed. However, the most general assumption would be that $C_{2}-C_{1}$ equals something other than zero.

3. Three compartments: If the volume were divided into three compartments, $V_{1}, V_{2}$, and $V_{3}$, by permeable membranes the equation would become

$$
\mathrm{A}=\mathrm{C}_{1} \mathrm{~V}_{1}+\mathrm{C}_{2} \mathrm{~V}_{2}+\mathrm{C}_{3} \mathrm{~V}_{3}+\mathrm{U}
$$

If one now adds and subtracts $\mathrm{C}_{1} \mathrm{~V}_{3}$ as well as $\mathrm{C}_{1} \mathrm{~V}_{2}$ and differentiates, then

$$
\begin{aligned}
0=\left(V_{1}+V_{2}+V_{3}\right) \frac{d C_{1}}{d t}+ & V_{2} \frac{d}{d t}\left(C_{2}-C_{1}\right) \\
& +V_{3} \frac{d}{d t}\left(C_{3}-C_{1}\right)+\frac{d U}{d t}
\end{aligned}
$$

Now, if the difference in the concentration of the substance in volumes $V_{3}$ and $V_{1}$ is constant, then $\left(C_{3}-C_{1}\right)$ becomes zero. And as above if $\left(C_{2}-C_{1}\right)$ again becomes zero, then

$$
V_{1}+V_{2}+V_{3}=-\frac{d U / d t}{d C_{1} / d t}
$$

or

Total $=$ Instantaneous rate of change of $\mathrm{U}$ with time Volume $=\frac{\text { Instantaneous rate of change of } C_{1} \text { with time }}{\text { Intang }}$

4. Practical application of the theory: Since one cannot measure the instantaneous rates of change of $U$ and $C$ with time, Equations 3, 6, and 7 are not in a useful form. One must make further simplifying assumptions, without deviating significantly from the theory, in the hope of obtaining a practical equation.
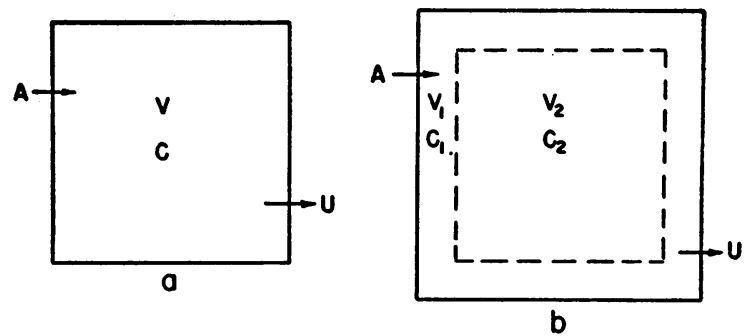

Fig. 1. a) One Compartment

A equals the amount of substance injected into volume V. $U$ is the loss of substance from V, and the average concentration of the substance is $C$.

\section{b) Two Compartments, $V_{1}$ and $V_{2}$ Separated by a Permeable Membrane}

The average concentrations of the substance in each compartment is $C_{1}$ and $C_{2}$.

Let us consider inulin as an indicator which is distributed in two phases of the extracellular fluid. Referring to Figure $1 \mathrm{~b}$, the following is defined:

$A=$ amount of inulin injected into volume $V_{1}$ in $\mathrm{mg}$.

$\mathrm{V}_{2}=$ interstitial volume in $\mathrm{cc}$.

$\mathrm{V}_{1}=$ intravascular volume in cc.

$\mathrm{C}_{1}=$ average plasma concentration of inulin in $\mathrm{mg}$. per cent.

$\mathrm{C}_{2}=$ average interstitial concentration of inulin in $\mathrm{mg}$. per cent.

$\mathrm{U}=$ urinary excretion of inulin in $\mathrm{mg}$.

$\mathrm{V}_{\mathrm{EC}}=\mathrm{V}_{1}+\mathrm{V}_{2}=$ volume of distribution of inulin.

After a single intravenous injection of inulin, the plasma inulin concentration versus time curve has the form shown in Figure 2, and the total urinary inulin excretion versus time curve has the form shown in Figure 3. Moreover, by measuring the plasma volume and the "extracellular volume" (volume of distribution of inulin) the virtual interstitial concentration of inulin may be calculated (4), and related to the plasma inulin concentration (Figure 2). It is important to note that soon after the plasma and the interstitial inulin concentrations are equal (where the curves cross at $P$ ) the curves are close together and appear to become parallel, with the interstitial inulin concentration at a higher value than the plasma inulin concentration. Now, referring to Equation 5, the error involved in assuming that the term $\left(C_{2}-C_{1}\right)$ is constant may not be significant. Most likely, $C_{2}$ is equal to $C_{1}$ at some time $P$, then $C_{2}$ is greater than $C_{1}$ and at infinity both $C_{1}$ and $C_{2}$ are equal to zero. For relatively short intervals of time, the two curves may be assumed to be parallel. Equation 6 may then be considered as an expression for the volume of distribution of inulin. This equation is valid only over the range of plasma inulin concentrations where the difference between interstitial and plasma inulin concentrations remains constant, or very nearly constant. This limitation in the use of the equation defines an equilibrium condition which should exist, or be approached, after a single injection of an indicator is given. As in other methods, the 


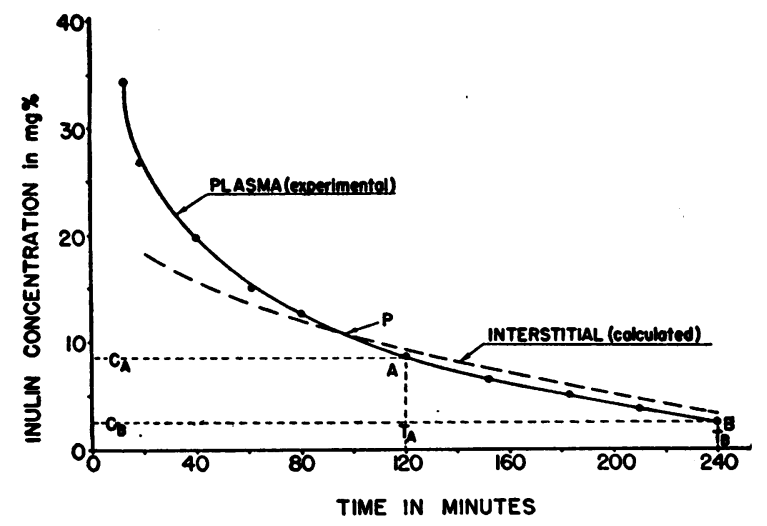

Fig. 2. Relationship of the Calculated Interstitial Inulin Concentration to the Plasma Inulin Concentration, Following a Single Intravenous Injection of this Substance at Time Zero

acceptable behavior of the substance is limited by the method.

If during this period, where the difference between plasma and interstitial inulin concentrations is assumed to remain constant, the plasma concentration and urinary excretion of inulin versus time curves approach a straight line, then there will be a small but probably insignificant error in assuming linear dependence of plasma concentration and urinary excretion with time. By making this assumption, the change of plasma inulin concentration over a finite period of time may be measured and substituted in Equation $\boldsymbol{\sigma}$ for the instantaneous rate of change of the plasma concentration with time. The change in urinary excretion of inulin over the same finite period of time can also be measured and substituted in the equation. For example, the plasma concentration of inulin is determined at 120 and 240 minutes after a single injection (A and $B$, Figure 2), and during this time the excreted inulin is measured (A to B, Figure 3). The apparent volume of distribution of inulin is then calculated as follows:

$$
\text { V. of D. of Inulin }=-\frac{U_{B}-U_{A} / T_{B}-T_{A}}{C_{B}-C_{A} / T_{B}-T_{A}}
$$

Since measurements are made over the same time interval, the equation simply becomes:

$$
\begin{aligned}
& \text { Volume of Distribution of Indicator }=\frac{U_{B}-U_{A}}{C_{A}-C_{B}} \\
& \text { Urinary excretion of indicator } \\
& \underset{\text { V. of D. of }}{\text { Indicator }}=\frac{\text { during time A to B }}{\begin{array}{c}
\text { Change in plasma concentration of the } \\
\text { substance during the same time interval }
\end{array}}
\end{aligned}
$$

In summary, the measurements should be made during the period where there is a constant, or nearly constant, difference between interstitial and plasma inulin concentration. Moreover, in order to follow the theory as closely as possible, that portion of the curve which most closely approximates a straight line should be used. Any amount of inulin is injected intravenously at time zero. At time A a blood sample is drawn and all urine up to this time is discarded. Another blood isample is drawn at time $B$ and all urine is collected from time A to B. After the appropriate corrections are made, the volume of distribution of the substance is calculated by dividing the urinary excretion of inulin during the time interval from $A$ to $B$ by the change in plasma inulin concentration during the same period. It is not necessary to know how much inulin was used because the calculation of the volume of distribution of the substance is independent of the amount of inulin injected.

Sample Calculation (see Figures 2 and 3).

After a single injection of about $4 \mathrm{gm}$. of inulin, the plasma water concentration was found to be $8.5 \mathrm{mg}$. per cent at 120 minutes and $2.5 \mathrm{mg}$. per cent at 240 minutes after injection. During this interval, $890 \mathrm{mg}$. of inulin were excreted in the urine:

$$
\text { V. of D. of Inulin }=\frac{890}{8.5-2.5} \times 100=14.8 \text { liters }
$$

N.B. In the constant-change method there is no need for correcting the plasma inulin concentration for the plasma inulinoid blank, because only the difference in plasma concentration is required for calculating the volume of distribution and not the actual values.

\section{METHODS}

Fifteen experiments on 6 normal healthy male physicians and 8 experiments on 4 adult mongrel female dogs comprise the basis of this report.

Inulin: Inulin was used as an indicator of the body fluid compartment measured in man. The subjects fasted from midnight the night preceding the test until the end of the experiment. On arising in the morning of the test, they emptied their bladders and drank two to three glasses of water. Samples of blood and urine were taken for the determinations of the concentration of inulinoid material. One intravenous injection of inulin was given, with the dose accurately measured in only one subject. Most subjects received approximately $50 \mathrm{cc}$. of 10 per cent inulin. Blood samples were collected from

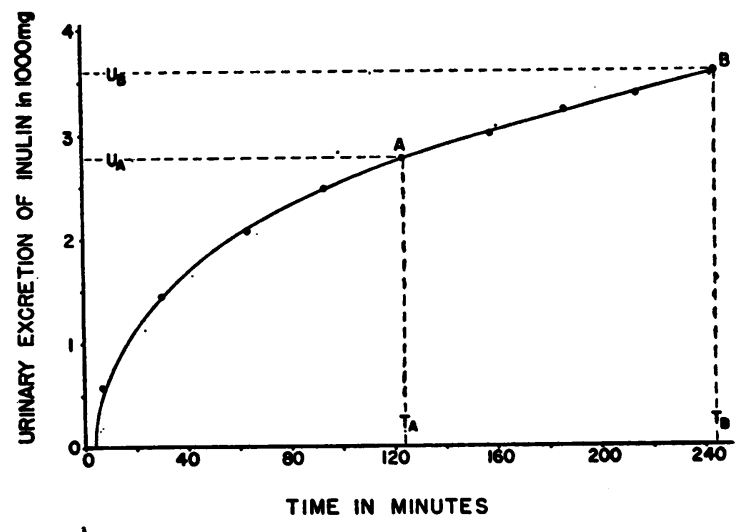

Fig. 3. Total Urinary Excretion of InUlin Following a Single Intravenous Injection of this SubSTANCE AT TIME Zero 
an antecubital vein at $150,180,240$, and 270 minutes after the injection. The urinary bladder was emptied by voiding, spontaneously, three to five minutes after each blood sample was drawn. To maintain an adequate urine flow, each individual drank $150 \mathrm{cc}$. of water every 30 to 60 minutes during the course of the experiment. The subjects were lying down throughout the test except for a few moments required to collect a urine sample. In a preliminary experiment, blood and urine samples were taken continuously every 20 to 30 minutes after a single injection of inulin, and the plasma volume was also determined, simultaneously, using T-1824 dye.

Mannitol and sucrose: The volumes of distribution of mannitol and sucrose were studied in dogs, anesthetized with sodium pentobarbital. The constant-infusion method, as described by Deane (8), was used in each of 4 dogs. Following a priming dose (1.5 gm. of each substance), a constant infusion of mannitol and sucrose (300 mg. per cent of each) in normal saline was given at the rate of 5 cc. per minute for a period of 2 hours. Three blood samples, fifteen minutes apart, were then taken to check the constancy of the plasma concentration of the indicator. After washing out the bladder, a normal saline infusion was given at a rate of $2 \mathrm{cc}$. per minute, and the urine was collected for at least 6 hours. Blood samples were withdrawn from the jugular vein and an indwelling catheter was used to collect the úrine.

The same 4 dogs were used to study the three single injection methods. The dogs were anesthetized and catheterized, as above. An intravenous infusion of normal saline was given at the rate of $5 \mathrm{cc}$. per minute. After the urine flow became adequate ( 1 to $3 \mathrm{cc}$. per minute), urine and blood blank samples were taken, and a single injection of $5 \mathrm{gm}$. of sucrose and $5 \mathrm{gm}$. of mannitol was given intravenously within 10 seconds. The saline infusion was maintained at $5 \mathrm{cc}$. per minute throughout the experiment. Blood samples were drawn at $120,150,180$, and 210 minutes after the injection. Urine samples were collected 2 minutes after each blood sample, and the bladder was washed out once with saline and air at the end of each collection period.

In all experiments, the subject was weighed at the end of the test. A careful record of fluid intake and output was kept in the dog experiments.

Analytical methods: Inulin and sucrose were determined by Schreiner's resorcinol technique (9), mannitol by the method of Corcoran and Page (10) and plasma volume was estimated by dilution of T-1824 dye using the procedure described by Chinard (11). Inulin determinations were made in duplicate, and mannitol and sucrose determinations in triplicate. In the animal experiments, plasma concentrations were converted to plasma water concentrations by dividing by 0.94 .

\section{CALCULATIONS}

Constant-infusion method: The volumes of distribution of sucrose and mannitol, obtained by using the constant-infusion method, were calculated by using the formula given by Deane ( 8 ).
Simple dilution method: After a single injection of an indicator, the volume of distribution was calculated as equal to the amount of material injected minus the amount of material excreted in the urine divided by the plasma concentration at any particular time.

Extrapolation method: The method described by Cardozo and Edelman (6) was used.

Constant-change method: The method described in this paper was used.

Wherever possible a comparison was made of the results obtained by each of these methods.

\section{RESULTS}

\section{The volume of distribution of inulin in man}

Since Equation 8 indicates that the calculation of the volume of distribution of a substance is independent of the amount of indicator given, a series of experiments were performed on the same individual using varying amounts of inulin as the indicator. Table I summarizes the results of these experiments. The subject received from 3008 to $5000 \mathrm{mg}$. of inulin on five different days. The volume of distribution of inulin by the constantchange calculation was found to be $16.2,16.0,16.2$, $16.2,{ }^{2}$ and $15.6^{2}$ per cent of body weight. The 2 Mean values.

mean value was 16.0 per cent and the standard deviation \pm 0.25 per cent of body weight.

The same data were used to calculate the volume of distribution by the simple dilution and extrapolation methods. The results of these calculations are also given in Table I. In all experiments the value for the volume of distribution of inulin obtained by either the simple dilution or extrapolation methods was higher than the figure obtained by the constant-change method. The simple dilution method indicates that the volume of distribution of inulin increases with time (from 30.3 to 59.2 per cent on 3-15-54). In this series of experiments a fair comparison has not been made with the extrapolation method, since only two values are used for the extrapolation in most experiments.

Table II summarizes the results of 10 experiments on 5 different individuals who received a single intravenous injection of inulin (about 5 $\mathrm{gm}$.) on two occasions. The volume of distribution has been calculated for three time intervals (150 to 240,150 to 270 , and 180 to 270 minutes after the injection). The mean value of the three periods is considered to be the best measure of the 
TABLE I

The volume of distribution of inulin in the same individual using different amounts of inulin with a comparison of three single injection methods

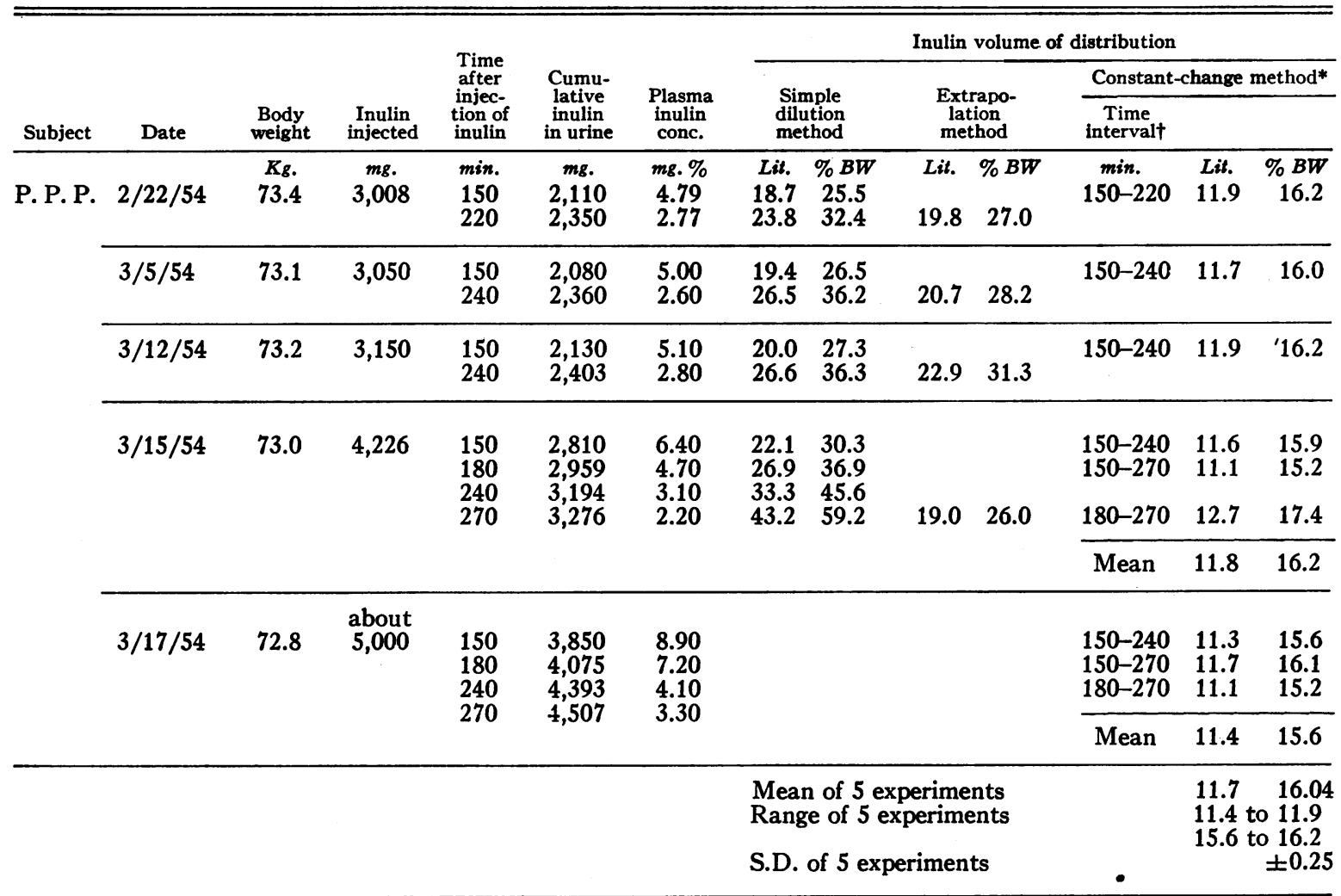

* Equation 8 was used.

$\dagger$ Time interval after single injection of inulin used for calculating the volume of distribution of inulin.

volume of distribution of inulin. A series of three experiments (R. H. F., J. E. P., and H. V. B.) showed a variation in the volume of distribution of inulin of less than one per cent of body weight. In one experiment (R.D.Q.) the variation was large (2.1 per cent), and the values obtained for the (150 to 240$)$ and (150 to 270$)$ time intervals differed by more than 15 per cent both on 3-30-54 and 4-17-54.

The mean value of the volume of distribution of inulin in the six individuals was found to be 18.7 per cent of body weight with a standard deviation of \pm 1.57 per cent.

\section{The volume of distribution of sucrose and man- nitol in dog}

Since Swan, Madisso, and Pitts (12) found in nephrectomized dogs that the volume of distribution of sucrose averaged 91 per cent ( 84 to 99 per cent) of the mannitol volume, a series of experi- ments were designed to determine whether or not a similar result would be obtained on intact animals. Moreover, the methods used to calculate the volume of distribution of a substance could be compared.

Table III summarizes the results of four experiments on four dogs, which received a single injection of $5 \mathrm{gm}$. of sucrose and $5 \mathrm{gm}$. of mannitol. Observations of the plasma level of the indicators were made at $120,150,180$, and 210 minutes after the injection. The amount of inulin excreted in the urine was measured at the end of each period. It is clear from Table III that the simple dilution method never gives a relatively constant value for the volume of distribution of a substance from 120 to 210 minutes after the single injection. The calculated volume of distribution of sucrose may vary as much as 162 per cent of body weight (Exp. 13, 54.1 to 216 per cent), and the calculated mannitol distribution may increase 
SINGLE IN JECTION METHOD

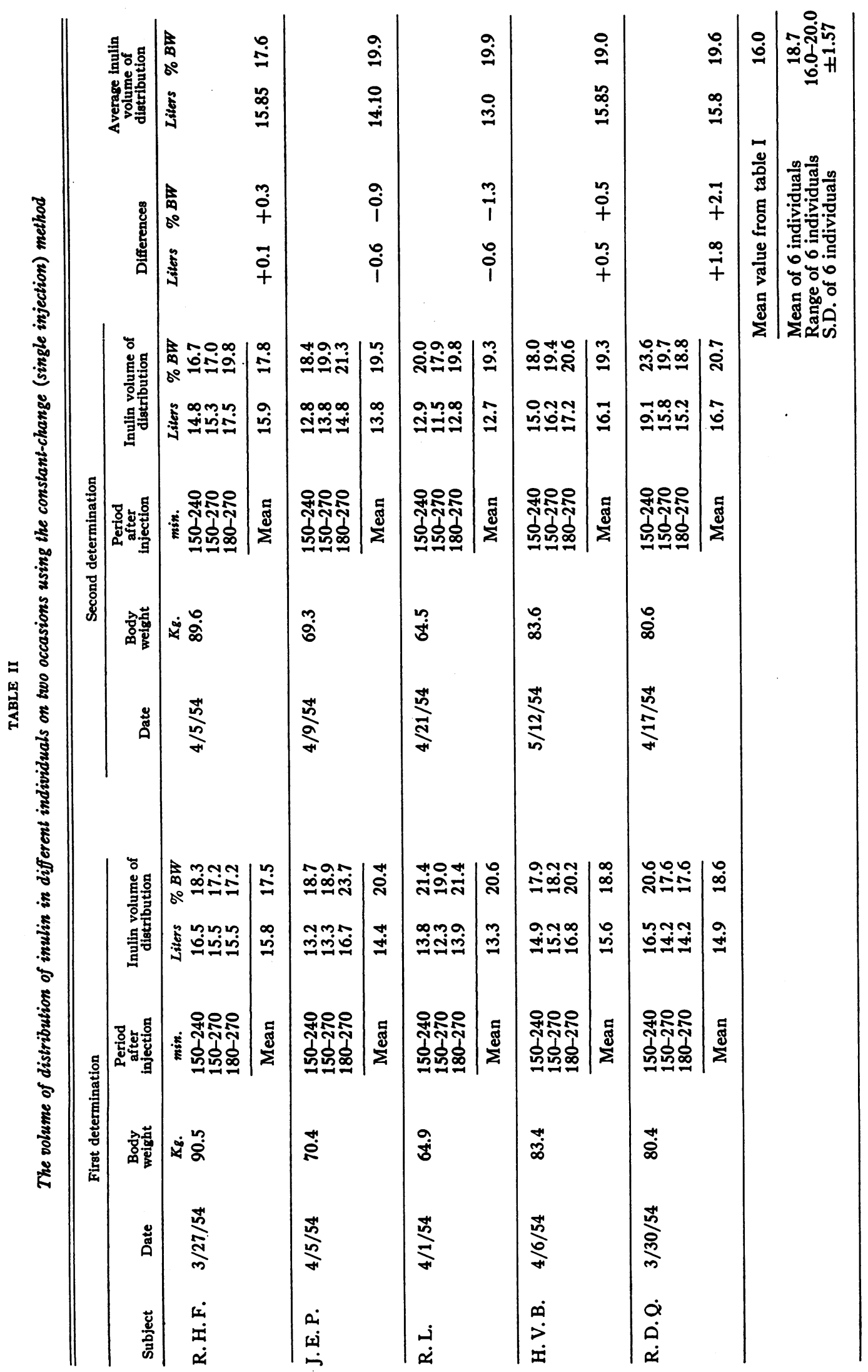


PETER P. POULOS

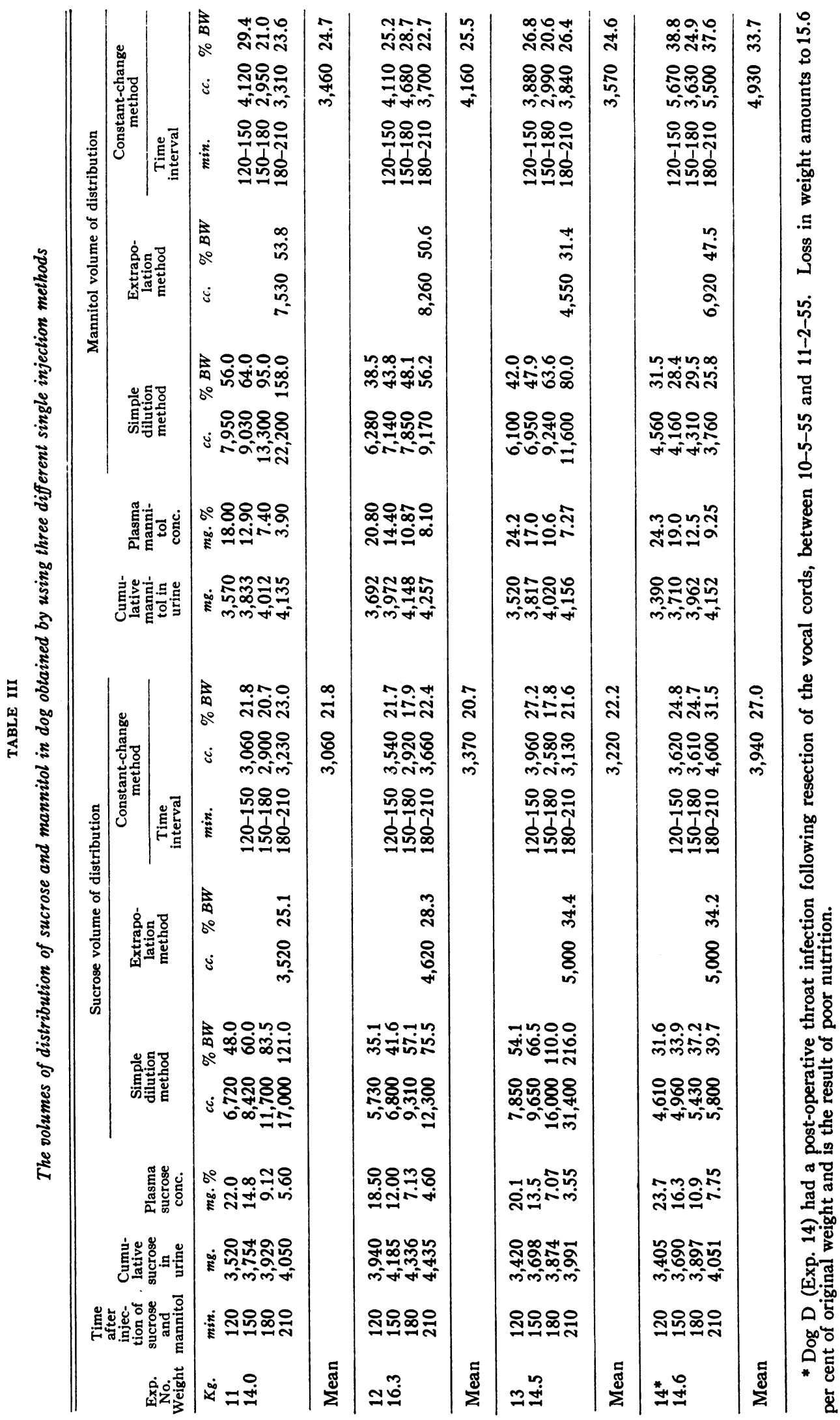


by 102 per cent of body weight (Exp. 11, 56.0 to 158 per cent).

The extrapolation method indicates that the volume of distribution of sucrose may vary by 9.3 per cent (25.1 to 34.4 per cent) in different animals, whereas, the mannitol distribution may vary by 22.4 per cent of body weight ( 31.4 to 53.8 per cent). However, all the values obtained by the extrapolation method may not be correct. The plotted values of the logarithm of the plasma concentration against time must demonstrate linearity within the limits of error of the experiment or extrapolation is invalid (6). This requirement was not adequately fulfilled in some experiments, and the variation in the mannitol distribution may indicate that the extrapolation was unacceptable. Regardless of the source of error, the fact remains that the entire experiment must be repeated in order to obtain a single value of the volume of distribution of a substance by the extrapolation method.

The volumes of distribution of both sucrose and mannitol remained relatively constant during the 120 to 210 -minute period of the experiment. In experiment 11, the distribution of sucrose increased from $3060 \mathrm{cc}$. (120 to $150 \mathrm{~min}$.) to 3230 cc. (180 to $210 \mathrm{~min}$ ), and from 120 to $210 \mathrm{~min}$ utes the animal retained 224 cc. of the infusion.
This small change in body fluid was not reflected in the volume of distribution of mannitol. Until further experimentation proves otherwise, the mean value of the three periods is considered to be the best measure of the volume of distribution of the indicator in these experiments. In experiments 11,12 , and 13 sucrose was distributed in a body fluid volume which represented, respectively, 21.8, 20.7 and 22.2 per cent of body weight. In these same experiments, the volume of distribution of mannitol was found to be $24.7,25.5$, and 24.6 per cent of body weight.

At an earlier date, the constant-infusion method was used to determine, simultaneously, the volume of distribution of sucrose and mannitol in the four dogs of the above experiments. A comparison of the volumes of distribution of sucrose and mannitol, obtained by the constant-infusion and constant-change (single injection) methods, is presented in Table IV. In all experiments the constant-infusion method gave smaller values for the distribution of the indicators than the constantchange method. The average value for the volume of distribution of sucrose was 19.4 per cent body weight by the constant-infusion method, and 21.6 per cent by the single injection method. Mannitol was found to be distributed in a larger body fluid volume than sucrose by both methods. The

TABLE IV

The volumes of distribution of sucrose and mannitol in dogs obtained by the constant-infusion and constant-change (single injection) methods

\begin{tabular}{|c|c|c|c|c|c|c|c|c|c|c|}
\hline & \multicolumn{2}{|c|}{$\operatorname{Dog} A$} & \multicolumn{2}{|c|}{$\operatorname{Dog} B$} & \multicolumn{2}{|c|}{ Dog C } & \multicolumn{2}{|c|}{ Dog D } & \multicolumn{2}{|c|}{ Mean values } \\
\hline & $\begin{array}{l}\text { Constant } \\
\text { infusion } \\
\text { method }\end{array}$ & $\begin{array}{c}\text { Single } \\
\text { injection } \\
\text { method }\end{array}$ & $\begin{array}{l}\text { Constant } \\
\text { infusion } \\
\text { method }\end{array}$ & $\begin{array}{c}\text { Single } \\
\text { injection } \\
\text { method }\end{array}$ & $\begin{array}{l}\text { Constant } \\
\text { infusion } \\
\text { method }\end{array}$ & $\begin{array}{c}\text { Single } \\
\text { injection } \\
\text { method }\end{array}$ & $\begin{array}{l}\text { Constant } \\
\text { infusion } \\
\text { method }\end{array}$ & $\begin{array}{c}\text { Single } \\
\text { injection } \\
\text { method }\end{array}$ & $\begin{array}{l}\text { Constant } \\
\text { infusion } \\
\text { method }\end{array}$ & $\begin{array}{c}\text { Single } \\
\text { injection } \\
\text { method }\end{array}$ \\
\hline 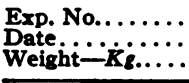 & $\begin{array}{l}.6 \\
.10-10-55 \\
. \quad 15.3\end{array}$ & $\begin{array}{c}11 \\
10-24-55 \\
14.0\end{array}$ & $\begin{array}{c}9 \\
10-17-55 \\
16.35\end{array}$ & $\begin{array}{c}12 \\
10-26-55 \\
16.3\end{array}$ & $\begin{array}{c}7 \\
10-12-55 \\
15.1\end{array}$ & 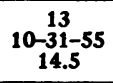 & $\begin{array}{c}10-5-55 \\
17.3\end{array}$ & $\begin{array}{c}14^{*} \\
11-2-55 \\
14.6^{*}\end{array}$ & & \\
\hline \multicolumn{11}{|c|}{ Sucrose volume of distribution } \\
\hline $\begin{array}{l}\text { cc. } \\
\% \text { BW } \\
\% \mathrm{BW}\end{array}$ & $\begin{array}{r}2,958 \\
19.3\end{array}$ & $\begin{array}{r}3,060 \\
21.8\end{array}$ & $\begin{array}{r}3,085 \\
18.9\end{array}$ & $\begin{array}{r}3,370 \\
20.7\end{array}$ & $\begin{array}{r}2,926 \\
19.4\end{array}$ & $\begin{array}{r}3,220 \\
22.2\end{array}$ & $\begin{array}{r}3,450 \\
20.0\end{array}$ & $\begin{array}{r}3,940 \\
27.0 \dagger\end{array}$ & 19.4 & 21.6 \\
\hline \multicolumn{11}{|c|}{ Mannitol volume of distribution } \\
\hline $\begin{array}{l}\text { cc. } \\
\% \text { BW } \\
\% \text { BW }\end{array}$ & $\begin{array}{r}3,440 \\
22.5\end{array}$ & $\begin{array}{r}3,460 \\
24.7\end{array}$ & $\begin{array}{r}3,624 \\
22.2\end{array}$ & $\begin{array}{r}4,160 \\
25.5\end{array}$ & $\begin{array}{r}3,560 \\
23.5\end{array}$ & $\begin{array}{r}3,570 \\
24.6\end{array}$ & $\begin{array}{r}4,310 \\
24.9\end{array}$ & $\begin{array}{r}4,930 \\
33.7 \dagger\end{array}$ & 23.3 & 24.9 \\
\hline \multicolumn{11}{|c|}{ Sucrose/mannitol } \\
\hline$\%$ & 85.8 & 88.2 & 85.1 & 81.2 & 82.6 & 90.2 & 80.3 & 80.2 & 83.4 & 84.9 \\
\hline
\end{tabular}


distribution of mannitol was 23.3 per cent body weight by the infusion method, and 24.9 per cent by the single injection method. The volume of distribution of sucrose, as a per cent of mannitol distribution, was $85.8,85.1,82.6$, and 80.3 (mean 83.4 ) by the constant-infusion method, and 88.2 , $81.2,90.2$, and 80.2 (mean 84.9 ) by the method of constant change. The variation is less by the infusion method ( 80.3 to 85.8 ) than by the single injection method ( 80.2 to 90.2 ).

The results obtained in experiment 14 (Table III and IV) are of particular interest in that the dog underwent a period of starvation after the constant-infusion and before the constant-change experiments were performed. The dog lost 15.6 per cent body weight ( 17.3 to $14.6 \mathrm{~kg}$.). Both the sucrose and mannitol volumes of distribution were significantly greater than in the "normal" dogs of experiments 11,12 , and 13 (27.0 as compared to 21.8, 20.7, and 22.2 per cent for sucrose and 33.7 as compared to $24.7,25.5$, and 24.6 per cent for mannitol).

\section{DISCUSSION}

\section{Comparison with other methods}

It is difficult to compare the various methods used for the estimation of the volume of distribution of a substance, because the limitations of each method must be carefully considered. Furthermore, the "ideal" properties and acceptable behavior of the indicator may vary with each method. Moreover, after the substance has been introduced into the body, the "equilibrium conditions" for one method may not satisfy the equilibrium, or steady state, requirements of another method. Nevertheless, an attempt will be made to compare the constant-change method with the simple dilution, extrapolation, and constant-infusion methods.

The data presented in Tables II and III indicate that the volume of distribution of the indicator, calculated on the basis of the simple dilution method, does not remain constant or even relatively constant, between 120 and 270 minutes after the start of the experiment. It may be that the proper time intervals were not used, or the plasma concentrations of the indicator may have been too low (mostly below $20 \mathrm{mg}$. per cent) for accurate analysis. Elkinton (13) found that, in a majority of experiments on man, the volume of distribution of mannitol remained unchanged between 1 and 3 hours, when the plasma mannitol concentration was kept relatively high (about 20 to $80 \mathrm{mg}$. per cent). He felt that, after 3 hours, the analytical error, in determining the plasma level of mannitol, was too great to draw any conclusions. Using Elkinton's data (13), the volume of distribution of mannitol was calculated by the constant-change method and compared with the values obtained by the simple dilution method (Table V). Elkinton felt that equilibrium was attained between 30 and 60 minutes after a single injection of mannitol had been given. Equilibrium was indicated when the plot of the logarithm of the plasma concentration of mannitol against time became a straight line, and also, by a constant value for the volume of distribution between two separate points. Table $\mathrm{V}$ shows that the volume of distribution of mannitol, during the 120 to 180-minute interval, by the constant-change method remains very constant in one individual on three occasions (RE-21.0, 20.7, and 20.7 per cent), and fairly constant in another individual on two occasions (LG-22.1 and 21.4 per cent). Moreover, "equilibrium," as regards the constantchange method, probably was not attained in subject $R E$ until 120 minutes, since the values for the distribution of mannitol are low and inconstant before this time. Here is an example of the meaning of equilibrium changing with the method which is used to calculate the volume of distribution of the substance. Furthermore, Kruhoffer's definition of equilibrium, constant and equal concentrations of the indicator in both the interstitial fluid and plasma water, differs from the above and meets the requirements of calculating the distribution of a substance by another method.

The amount of material injected into the body must be measured accurately in using the simple dilution method, but may be ignored in the constant-change method (Equation 8 and Table III). In the simple dilution method, as well as in the extrapolation and constant-infusion methods, the indicator must be completely excreted or accounted for before the distribution of a substance can be determined following a second injection. There is no such limitation in the constant-change method.

It would not be fair to compare the extrapola- 
TABLE V

The volume of distribution of mannitol in two individuals obtained by using three different single injection methods (data from literature-Elkinton (13))

\begin{tabular}{|c|c|c|c|c|c|c|c|c|}
\hline \multirow{5}{*}{$\begin{array}{c}\begin{array}{c}\text { Subject } \\
\text { weight }\end{array} \\
\begin{array}{r}K g . \\
\text { RE-1 } \\
70.17\end{array}\end{array}$} & \multirow{5}{*}{$\begin{array}{c}\begin{array}{c}\text { Time } \\
\text { after } \\
\text { injec- } \\
\text { tion of } \\
\text { mannitol }\end{array} \\
\text { min. } \\
30 \\
60 \\
120 \\
180\end{array}$} & \multicolumn{7}{|c|}{ Volume of distribution of mannitol } \\
\hline & & \multirow{2}{*}{\multicolumn{2}{|c|}{$\begin{array}{l}\text { Simple dilution } \\
\text { method* }\end{array}$}} & \multirow{2}{*}{\multicolumn{2}{|c|}{$\begin{array}{c}\text { Extrapolation } \\
\text { method }\end{array}$}} & \multicolumn{3}{|c|}{ Constant-change method } \\
\hline & & & & & & \multicolumn{3}{|l|}{$\begin{array}{c}\text { Time } \\
\text { interval }\end{array}$} \\
\hline & & $\begin{array}{l}\text { Liters } \\
12.0\end{array}$ & $\begin{array}{c}\% B W \\
17.1\end{array}$ & Liters & $\% B W$ & $m i n$. & & \\
\hline & & $\begin{array}{l}13.1 \\
16.5 \\
17.6\end{array}$ & $\begin{array}{l}18.7 \\
23.5 \\
25.1\end{array}$ & 12.9 & 18.4 & $\begin{array}{c}30-60 \\
60-120 \\
120-180\end{array}$ & $\begin{array}{r}8.9 \\
9.0 \\
14.7\end{array}$ & $\begin{array}{l}12.6 \\
12.8 \\
21.0\end{array}$ \\
\hline \multirow{5}{*}{$\begin{array}{l}\text { RE-2 } \\
69.85\end{array}$} & 30 & 12.2 & 17.5 & & & & & \\
\hline & 60 & 13.5 & 19.3 & & & $30-60$ & 8.5 & 12.6 \\
\hline & 90 & 13.6 & 19.5 & & & $60-90$ & 13.8 & 19.7 \\
\hline & 120 & 13.3 & 19.0 & & & $90-120$ & 15.9 & 22.8 \\
\hline & 180 & 16.0 & 22.9 & 14.1 & 20.4 & $120-180$ & 14.4 & 20.7 \\
\hline \multirow{4}{*}{$\begin{array}{l}\text { RE-3 } \\
70.78\end{array}$} & 30 & 12.1 & 17.1 & & & & & \\
\hline & 60 & 13.6 & 19.2 & & & $30-60$ & 8.3 & 11.7 \\
\hline & 90 & 14.4 & 20.3 & & & $\begin{array}{l}00-90 \\
00-120\end{array}$ & 10.4 & 14.7 \\
\hline & 180 & 14.6 & 20.6 & 14.8 & 20.9 & $120-180$ & 14.6 & 20.7 \\
\hline \multirow{5}{*}{$\begin{array}{l}\text { LG-1 } \\
67.3\end{array}$} & 30 & 13.9 & 20.5 & & & & & \\
\hline & 60 & 15.4 & 22.8 & & & $30-60$ & 9.6 & 14.2 \\
\hline & 90 & 15.3 & 22.6 & & & $60-90$ & 16.1 & 23.8 \\
\hline & 120 & 15.3 & 22.6 & & & $90-120$ & 16.4 & 24.2 \\
\hline & 180 & 15.3 & 22.6 & 17.3 & 25.6 & $120-180$ & 14.9 & 22.1 \\
\hline \multirow{4}{*}{$\begin{array}{l}\text { LG-2 } \\
68.46\end{array}$} & 30 & 14.2 & 20.8 & & & & & \\
\hline & 60 & 15.7 & 23.0 & & & $30-60$ & 10.2 & 14.9 \\
\hline & $y 0$ & 16.0 & 23.4 & & & $60-90$ & 14.7 & 21.5 \\
\hline & $\begin{array}{l}120 \\
180\end{array}$ & $\begin{array}{l}10.0 \\
16.8\end{array}$ & $\begin{array}{l}23.4 \\
24.6\end{array}$ & 17.0 & 24.8 & $120-180$ & $\begin{array}{l}15.9 \\
14.6\end{array}$ & $\begin{array}{l}23.2 \\
21.4\end{array}$ \\
\hline
\end{tabular}

* Calculated by Elkinton.

tion and constant-change methods on the basis of data presented in Tables II and III since the extrapolation, in some experiments, did not meet the requirements of the method as described by Cardozo and Edelman (6).

As indicated by Table IV, in all experiments the constant-infusion method gave smaller values for the distribution of sucrose, as well as mannitol, than the constant-change method. A possible reason for this is that, after the constant infusion was stopped, all of the indicator in the animal was not recovered. Deane (8) states that for inulin the urine should be collected for at least 5 hours in dog, after the infusion is discontinued. It would appear that the 6-hour collection period used in these experiments should have been sufficient for recovering all of the sucrose and mannitol, since these substances have a molecular weight smaller than that of inulin. It may be that all of the injected sucrose and mannitol could never be recovered.
The volume of distribution of inulin in man, estimated by the constant-infusion method, has been reported as representing 16 per cent of body weight (14). The mean value obtained by the constant-change method was 18.7 per cent (Table II). Again, it appears likely that all of the injected inulin was not recovered in the infusion method. In man, the constant-infusion method requires 6 hours of inulin infusion plus 18 to 24 hours of urinary collection, whereas the constantchange method requires about $4 \frac{1}{2}$ hours, if the longest time interval is used. The fact that the indicator is rapidly excreted by glomerular filtration is an advantage in the constant-change method, but a disadvantage in the infusion method $(2,5)$. The time required to determine the volume of distribution of a substance by the constant-change method is shortened if the substance diffuses and is excreted more rapidly.

The observation that the volume of distribution of sucrose is about 80 to 90 per cent of the man- 
nitol distribution in intact animals, confirms the work of Swan, Madisso, and Pitts (12) who worked with nephrectomized dogs. Moreover, the values obtained for the distribution of sucrose and mannitol as a per cent of body weight compared fairly well. (Sucrose: Intact animals; mean 21.6 and range 20.7 to 22.2 per cent. Nephrectomized; mean 21.3 and range 18.8 to 25.0 per cent. Mannitol: Intact animals; mean 24.9 and range 24.6 to 25.5 per cent. Nephrectomized; mean 22.6 and range 18.7 to 27.2.) The question of whether or not the volume of distribution of inulin, sucrose, or mannitol is a measure of the extracellular fluid in intact animals cannot be answered by the present investigation.

\section{An analysis of the basic assumptions}

The first, implicit, assumption is that the body fluid compartment which is being measured does not change with time, during the period of measurement. How long the body fluid compartment must remain constant depends upon the indicator. A short time interval could be used if the concentration of the indicator could be very accurately determined. If a short time interval were used with inulin, for example, the error of the chemical determination of the substance would unduly influence the result. So, with inulin a long time interval is desirable and the body fluid compartment would have to remain constant during the period of observation. Perhaps a radio-active indicator, which avoids dealing with plasma and urine "blanks" and which can be accurately measured, may allow the use of relatively short intervals of time.

If one were able to use Equation (5), no other assumptions would be necessary. However, Equation (5) cannot be used directly, and certain simplifying assumptions must be made in order to obtain a useful Equation (8). The second assumption is that, for a two volume system such as the extracellular fluid, the difference between the interstitial and plasma indicator concentrations remains constant, or very nearly constant, during the period of measurement, so that the term, $V_{2} \frac{d}{d t}\left(C_{2}-C_{1}\right)$, of Equation (5) can be eliminated. This condition of constant difference, during short intervals of time, is approached some time after point $P$ shown in Figure 2 (using in- ulin as an example). The third assumption is that, during the period of measurement, the plasma concentration of the indicator and the urinary excretion of the indicator versus time curves approach a straight line. The three assumptions are interrelated and depend a great deal upon the indicator, which more than anything else, determines the length of the measurement period. All three assumptions become more valid as the period of measurement is shortened.

\section{Steady state conditions}

The above assumptions define the steady state conditions which should exist, or be approached, after a substance is introduced into the body, if the constant-change method is to be used for determining the volume of distribution of that substance. It is felt that, following a single intravenous injection of an indicator, a steady state exists when the value of the distribution of the substance, calculated on the basis of many time intervals, remains relatively constant.

\section{Ideal substance}

In order to use the method of constant-change, an ideal substance should possess the following properties: 1) It should be distributed in the body fluid volume which is to be measured. 2) It should diffuse and be excreted in the urine rapidly. A rapid change in plasma concentration of the indicator is desirable, since a shorter period of time would be required to measure significant differences in plasma concentration and urinary excretion of the indicator. Many observations could be made over a short period of time, so that numerous confirmatory calculations of the volume of distribution of the indicator could be obtained. 3) During the period of measurement, the extrarenal loss of the indicator should be insignificant. The total amount of indicator which leaves the volume, prior to measurement, is unimportant. 4) It should not change the body fluid volume which is to be measured. 5) It should not be toxic. 6) It should be determined accurately.

\section{SUMMARY}

1. A constant-change, single injection method is presented for estimating the apparent volume of 
distribution of substances in body fluid compartments of intact animals. For a two compartment system, the extracellular space for example, the apparent volume of distribution of an indicator equals the urinary excretion of the indicator during a certain time interval divided by the change in plasma indicator concentration during the same time interval. Theoretical and experimental justification is presented for selecting and identifying the proper time interval: 1) the volume of distribution of the indicator should not change during the period of measurement, 2) the difference in interstitial and plasma indicator concentrations should remain constant, or very nearly constant, 3 ) during the time interval, the plasma concentration of the indicator and the urinary excretion of the indicator versus time curves should approach a straight line. The limitations of the basic assumptions, used in deriving the above equation, are analyzed. The basic assumptions define equilibrium conditions which should exist, if the constant-change method is to be used. For best results the method should be utilized with a substance which has the following ideal properties: 1) It should be distributed in the body fluid volume which is to be measured. 2) It should distribute and be eliminated from the body rapidly. 3 ) During the period of measurement, the extrarenal loss of the indicator should be insignificant. 4) It should not change the body fluid volume which is to be measured. 5) It should not be toxic. 6) It should be determined accurately.

2. The constant-change method is compared with the simple dilution, extrapolation, and constant-infusion methods and found to have the following advantages: 1 ) It is independent of the amount of indicator used, and 2) prior to the period of measurement, it is unrelated to the amount of indicator lost from the fluid compartment in which the indicator is distributed. 3) The indicator need not be completely excreted before the distribution of a substance can be determined following a second injection. 4) It offers the possibility of estimating small changes in the distribution of the indicator. 5) It requires that only the relative change in plasma concentration of the indicator be measured.

3. The volume of distribution of inulin averaged 18.7 per cent of body weight in 6 normal individuals. (Range 16.0 to 20.0 per cent and standard deviation \pm 1.57 per cent.)

4. The volume of distribution of sucrose, as a per cent of the mannitol distribution, averaged 84.9 (80.2 to 90.2$)$ in four dogs.

\section{REFERENCES}

1. Kruhoffer, $P$., Inulin as an indicator for the extracellular space. Acta physiol. Scandinav., 1946, 11, 16.

2. Guadino, M., and Levitt, M. F., Inulin space as a measure of extracellular fluid. Am. J. Physiol., 1949, 157, 387.

3. Guadino, M., Kinetics of distribution of inulin between two body water compartments. Proc. Soc. Exper. Biol. \& Med., 1949, 70, 672.

4. Schachter, D., Freinkel, N., and Schwartz, I. L., Movement of inulin between plasma and interstitial fluid. Am. J. Physiol., 1950, 160, 532.

5. Guadino, M., Schwartz, I. L., and Levitt, M. F., Inulin volume of distribution as a measure of extracellular fluid in dog and man. Proc. Soc. Exper. Biol. \& Med., 1948, 68, 507.

6. Cardozo, R. H., and Edelman, I. S., The volume of distribution of sodium thiosulfate as a measure of the extracellular fluid space. J. Clin. Invest., 1952, $31,280$.

7. Newman, E. V., Bordley, J., III, and Winternitz, J., The interrelations of glomerular volume, filtration rate (mannitol clearance), extracellular fluid, surface area of the body, and plasma concentration of mannitol. A definition of extracellular fluid clearance determined by following plasma concentration after a single injection of mannitol. Bull. Johns Hopkins Hosp., 1944, 75, 253.

8. Deane, N., Constant infusion-urine collection technique in Methods in Medical Research, Corcoran, A. C., Ed., Year Book Publishers, 1952, Vol. 5, p. 160.

9. Schreiner, G. E., Determination of inulin by means of resorcinol. Proc. Soc. Exper. Biol. \& Med., 1950, 74, 117.

10. Corcoran, A. C., and Page, I. H., A method for the determination of mannitol in plasma and urine. J. Biol. Chem., 1947, 170, 165.

11. Chinard, F. P., Estimation of plasma volume by dye dilution method in Methods in Medical Research. M. B. Visscher, Ed., Chicago, Year Book Publishers, 1951, Vol. 4, p. 38.

12. Swan, R. C., Madisso, H., and Pitts, R. F., Measurement of the extracellular fluid volume in nephrectomized dogs. J. Clin. Invest., 1954, 33, 1447.

13. Elkinton, J. R., The volume of distribution of mannitol as a measure of the volume of extracellular fluid, with a study of the mannitol method. J. Clin. Invest., 1947, 26, 1088.

14. Levitt, M. F., and Guadino, M., Measurement of body water compartments. Am. J. Med., 1950, 9, 208. 